\title{
Association between Toll-Like Receptor 4 and Occurrence of Type 2 Diabetes Mellitus Susceptible to Pulmonary Tuberculosis in Northeast China
}

\author{
Yuze Li, ${ }^{1,2}$ Dianzhong Li, ${ }^{2}$ Jinfeng Zhang, ${ }^{1}$ Shurui Liu, ${ }^{1}$ Haijun Chen, ${ }^{3}$ and Kun Wu ${ }^{1}$ \\ ${ }^{1}$ Department of Nutrition and Food Hygiene, School of Public Health, Harbin Medical University, Harbin 150081, China \\ ${ }^{2}$ Department of the Fourth Internal Medicine, The Fourth Hospital of Heilongjiang Province, Harbin 150500, China \\ ${ }^{3}$ CT Department, Heilongjiang Province Hospital, Harbin 150036, China \\ Correspondence should be addressed to Kun Wu; wukun_15000@126.com
}

Received 2 December 2015; Revised 3 March 2016; Accepted 13 March 2016

Academic Editor: Yingmei Feng

Copyright (C) 2016 Yuze Li et al. This is an open access article distributed under the Creative Commons Attribution License, which permits unrestricted use, distribution, and reproduction in any medium, provided the original work is properly cited.

\begin{abstract}
The purpose of this study is to explore why type 2 diabetes mellitus (T2DM) patients are susceptible to pulmonary tuberculosis through detection of serum Toll-like receptor $4\left(\mathrm{TLR}_{4}\right)$, an important immune-related receptor, especially in terms of content and $\mathrm{TLR}_{4}$ gene polymorphism. Patients with T2DM complicated by pulmonary tuberculosis (T2DMTB) were selected as the case group and T2DM patients without tuberculosis were selected as the control group. Forty patients in each group were randomly selected and their serum $\mathrm{TLR}_{4}$ levels were detected and compared. Determination of six sites of $\mathrm{TLR}_{4}$ gene polymorphism was carried out in 238 T2DMTB patients and 310 patients with T2DM, and results showed that the serum TLR $_{4}$ content of the T2DMTB group was significantly lower than that of the T2DM group $(p<0.05)$. The six sites of $\mathrm{TLR}_{4}$ gene polymorphism did not show significant associations with T2DMTB risk. No statistically significant differences in genotype distributions were observed between T2DMTB patients and patients with T2DM when studied using the recessive and dominant genetic models. How two diseases with contradictory nutritional statuses can occur in the same person is difficult to explain from environmental factors perspective alone. Future research should study the causes of T2DMTB from the perspective of genetics.
\end{abstract}

\section{Introduction}

The prevalence of type 2 diabetes mellitus (T2DM) complicated by tuberculosis (TB) (T2DMTB) is rapidly increasing, resulting in detrimental effects on the economy and human health.

Clinical symptoms reveal that environmental factors play important roles in T2DM and TB. Because T2DMTB may be attributed to multiple causes, clinical experience indicates the traditional perspective that the two diseases are related in terms of nutrition. TB is associated with malnutrition, while T2DM is associated with excess nutrients. Thus, environmental factors, among which nutrition is one of the most important, alone, cannot explain the pathogenesis of two seemingly conflicting diseases occurring simultaneously in the same individual. In this case, genetic factors may be responsible for the development of T2DMTB [1-3], but we are not the first who are aware of host genetic factors that are important to determine the risk of type 2 diabetes mellitus complicated by tuberculosis. García-Elorriaga et al. [4] analyzed the association of inflammatory cytokine polymorphisms and T2DMTB in Mexico.

Toll-like receptor $4\left(\mathrm{TLR}_{4}\right)$, a pattern recognition receptor, can recognize pathogen-associated molecular patterns (PAMPs) [5] and exacerbate and release inflammatory cytokines, such as TNF- $\alpha$, IL-1 $\beta$, IL-6, and IFN- $\gamma$ [6]. Mycobacterium tuberculosis presents liposaccharides (LPS), a type of PAMP. When TLR 4 recognizes the LPS of M. tuberculosis, inflammatory cytokines are induced and released by the pathway of TLR T $_{4}$ 7-9]. This pathway is an important element in the innate immune system of the human body. $\mathrm{TLR}_{4}$, as an important mediator of inflammation, can recognize a variety of pathogens, including Gram-negative and Gram-positive bacteria [10]. Previous studies have shown that human TLR 4 
is a potentially important gene that may affect the onset of T2DM [11-13]. The receptor may be related to susceptibility to some infections that can induce diseases such as TBs [1418]. To date, no study has yet reported the association between $\mathrm{TLR}_{4}$ gene polymorphisms and the risk of T2DMTB in the Chinese population.

We believe that $\mathrm{TLR}_{4}$ gene polymorphisms are a good starting point for studying T2DMTB. To be able to establish preventive measures for high-risk people as far as possible, in this study, we investigate the relationship between $\mathrm{TLR}_{4}$ gene polymorphisms and T2DMTB risk in Northeast China.

\section{Material and Methods}

2.1. Study Subject and Sample Collection. We recruited 238 cases with T2DMTB as the case group and 310 cases with T2DM as the control group. T2DMTB patient information was obtained from the Fourth Medical Ward, Heilongjiang Province Tuberculosis Control Center, from September 2013 to June 2015. T2DM patient information was obtained from the Second Department of Outpatient Services, Heilongjiang Province Tuberculosis Control Center, from September 2013 to November 2014.

Subjects with a history of blood-transmitted diseases, such as AIDS, hepatitis B, hepatitis C, or other endocrine diseases, were excluded from this study. Blood samples were taken from the patients, and DNA was obtained and stored in $193 \mathrm{~K}$. Both doctors and study subjects provided consent to participate in this work, and the Ethics Committee of Harbin Medical University approved of this research.

2.2. Immunohistochemical Method. To determine whether serum $\mathrm{TLR}_{4}$ levels were consistent with the gene expression level, 40 serum samples were collected from the T2DMTB group and T2DM group, respectively, according to the principle of random. Serum $\mathrm{TLR}_{4}$ contents were detected by using an immunohistochemical method following the manufacturer's instructions (Beijing Cheng Lin Biological Technology Co., Ltd.).

2.3. Tag SNP Selection and Genotyping. Tag SNPs of $\mathrm{TLR}_{4}$ gene were evaluated and selected by using the HapMap database (https://hapmap.ncbi.nlm.nih.gov/) with the following criterion: a minor allele frequency $(\mathrm{MAF})>0.05$ in the Chinese Han population in the National Center of Biotechnology Information Database; linkage disequilibrium (LD) blocks were established by using Chinese LD maps and $r^{2}>0.8$. Six tag SNPs representing the genetic information of TLR 4 were selected for genotyping: rs1927914 located in the promoter region; rs11536879, rs1927911, and rs1927907 located in the intron region; and rs11536889 and rs7873784 located in the $3^{\prime}$-UTR region.

According to the manufacturer's instructions, genomic DNA was extracted from peripheral blood using a Tiangen DNA Blood Mini kit (Tiangen Biotech Co., Ltd., Beijing, China). All SNPs were genotyped using fluorogenic $5^{\prime}$-nuclease assay (TaqMan SNP Genotyping Assay, Applied Biosystems, Foster City, CA, USA). For quality control, $20 \%$ of all of the samples were performed in delicate form randomly for each SNP. The concordance rate of these repeated samples was $100 \%$.

2.4. Statistical Analysis. Numerical data are expressed as mean \pm SD. Student's $t$-test was performed to analyze differences between the T2DMTB and T2DM groups.

Fisher's exact test was used to evaluate the HardyWeinberg equilibrium (HWE) in the subjects. The chi-square test or Fisher's exact test was used to identify statistical differences in the distributions of clinic pathological characteristics. Univariate and multivariate unconditional logistic regression were used to estimate crude and adjusted odds ratios (ORs) and 95\% confidence intervals (CIs), all of which measured the associations between the risk factors of T2DMTB compared with T2DM. Two-sided $p<0.05$ was considered as statistically significant. Statistical analysis was carried out by using SAS software (version 9.1.3, SAS Institute, Cary, NC).

\section{Results}

3.1. Demographic Characteristics. A total of 548 people participated in this study, including 238 cases of T2MDTB and 310 cases of T2MD. Among the patients, 338 were male and 210 were female. The mean ages of T2DMTB and T2DM patients were $51.97 \pm 11.87$ years and $58.73 \pm 11.46$ years, respectively. The demographic characteristics of the patients are shown in Table 1.

3.2. Serum $\mathrm{TLR}_{4}$ Levels of Patients with T2DMTB and Patients with T2DM. The serum TLR $_{4}$ levels of subjects with T2DMTB were significantly lower than those of subjects suffering from T2DM $(p<0.0001)$. No differences in the basic characteristics of the participants, including gender $(p=0.260)$ and age $(p=0.631)$, were observed (Table 2$)$.

3.3. Distributions of SNP Genotypes between Patients with T2DMTB and Patients with T2DM. Genotype distributions did not show statistically significant deviations from HWE for all SNPs in this study (Table 3).

3.4. Distribution of Allelic Genes of SNPs between Patients with T2DMTB and Patients with T2DM. The distributions of allelic genes of six SNPs of the $\mathrm{TLR}_{4}$ gene were not statistically significant between patients with T2DMTB and patients with T2DM. Details of these distributions are summarized in Table 4.

3.5. SNPs and T2DMTB Risk. The SNPs of $\mathrm{TLR}_{4}$ were not significantly associated with T2DMTB risk. No significant differences in genotype distributions between patients with T2DMTB and patients with T2DM were observed using the recessive and dominant genetic models (Table 5). However, potential trends may provide useful information for future studies. In rs7873784, compared with the GG genotype, the 
TABLE 1: Demographic characteristics of the subjects.

\begin{tabular}{|c|c|c|c|c|}
\hline Variable & T2DMTB & T2DM & Total & $p$ value \\
\hline \multicolumn{5}{|l|}{ Age } \\
\hline$\leqslant 50$ & 104 & 68 & 172 & \multirow{4}{*}{$<0.0001$} \\
\hline $50-60$ & 73 & 108 & 181 & \\
\hline $60-70$ & 45 & 80 & 125 & \\
\hline$\geqslant 70$ & 16 & 54 & 70 & \\
\hline \multicolumn{5}{|l|}{ Gender } \\
\hline Male & 167 & 171 & 338 & \multirow{2}{*}{0.0003} \\
\hline Female & 71 & 139 & 210 & \\
\hline \multicolumn{5}{|l|}{ BMI } \\
\hline$\leqslant 18.5$ & 35 & 8 & 43 & \multirow{3}{*}{$<0.0001$} \\
\hline $18.5-24$ & 112 & 64 & 176 & \\
\hline$\geqslant 24$ & 91 & 238 & 329 & \\
\hline \multicolumn{5}{|l|}{ Smoking } \\
\hline Yes & 132 & 86 & 218 & \multirow{2}{*}{$<0.0001$} \\
\hline No & 106 & 224 & 330 & \\
\hline \multicolumn{5}{|l|}{ Drinking } \\
\hline Yes & 108 & 94 & 202 & \multirow{2}{*}{0.0003} \\
\hline No & 130 & 216 & 346 & \\
\hline \multicolumn{5}{|l|}{ Glucose } \\
\hline$<5.0$ & 12 & 13 & 25 & \multirow{3}{*}{0.0857} \\
\hline $5.0-7.2$ & 48 & 88 & 136 & \\
\hline$>7.2$ & 178 & 209 & 387 & \\
\hline \multicolumn{5}{|l|}{ Insulin use } \\
\hline Use & 112 & 196 & 308 & \multirow{3}{*}{$<0.0001$} \\
\hline No use & 126 & 112 & 238 & \\
\hline Unclear & 0 & 2 & 2 & \\
\hline \multicolumn{5}{|c|}{ Hypoglycemic drug use } \\
\hline Use & 45 & 224 & 269 & \multirow{3}{*}{$<0.0001$} \\
\hline No use & 193 & 80 & 273 & \\
\hline Unclear & 0 & 6 & 6 & \\
\hline
\end{tabular}

TABLE 2: Serum TLR $_{4}$ levels of patients with T2DMTB and T2DM.

\begin{tabular}{lccc}
\hline Variable & T2DMTB & T2DM & $p$ value \\
\hline Gender (male/female) & $40(20 / 20)$ & $40(25 / 15)$ & 0.260 \\
Age (years) & $51.17 \pm 6.70$ & $51.85 \pm 6.20$ & 0.631 \\
TLR $_{4}(\mathrm{ng} / \mathrm{mL})$ & $15.27 \pm 2.52$ & $19.40 \pm 1.80$ & $<0.0001$ \\
\hline
\end{tabular}

GC genotype presented lower risks of T2DMTB $\left(\mathrm{OR}_{\text {adjusted }}=\right.$ $0.69,95 \%$ CI: $0.42-1.14, p=0.15)$. In rs11536879, AG genotype carriers showed decreased risk of T2DMTB compared with the GG genotype $\left(\mathrm{OR}_{\text {adjusted }}=0.68,95 \% \mathrm{CI}\right.$ : $0.43-1.08$, $p=0.10)$.

\section{Discussion}

A previous study showed that patients with T2DM demonstrated four to eight times increased risk of tuberculosis compared to patients without T2DM. For instance, TB in T2DM patients was 5 times more prevalent than in nonT2DM patients in some regions in the USA, 5.4 times more prevalent than in non-T2DM patients in Australia, and 6.8 times more prevalent than in non-T2DM patients in Mexico [4].

In the clinic, we discovered that T2DMTB patients present uneven changes in inflammatory cytokines such as TNF- $\alpha$ and IFN- $\gamma$. Clinical examination of simple TB yielded a positive IFN- $\gamma$ test, but the results of nearly all patients with T2DMTB were negative. $\mathrm{TLR}_{4}$ is an important element of the endogenic immune system and it can induce and release inflammatory cytokines [5]. TLR 4 is an important element of the innate immune system of the human body. Thus, we hypothesize that serum $\mathrm{TLR}_{4}$ exhibits obvious changes in T2DMTB patients. We examined $\mathrm{TLR}_{4}$ serum levels in patients with T2DMTB and patients T2DM to determine whether $\mathrm{TLR}_{4}$ is involved in the susceptibility of T2DM patients suffering from TB in Northeast China. While no study has yet proven that $\mathrm{TLR}_{4}$ polymorphisms are related to T2DMTB or T2DM, other studies [19-22] indicate that TLR polymorphisms present statistically significant differences between healthy people and patients with TB.

Our study results are different from those of $\mathrm{Wu}$ et al. [23], especially in terms of the frequencies of the GG genotype of SNP rs7873784 in $\mathrm{TLR}_{4}(\mathrm{OR}=2.136$; 95\% CI: $1.312-$ 3.478 ) and the CC genotype of rs3764879 in $\mathrm{TLR}_{8}(\mathrm{OR}=$ 1.982; 95\% CI: 1.292-3.042). It was also significantly higher in the TB group than in the healthy group. Arji et al. [24] found $\mathrm{TLR}_{4}$ interactions influencing protection against $\mathrm{TB}$ in Moroccan patients. The present work and that of Jahantigh et al. [25] both demonstrated no significant relation between $\mathrm{TLR}_{4}$ and $\mathrm{TLR}_{9}$ polymorphisms and TB. Sánchez et al. [26] reported that they did not find any association between $\mathrm{TLR}_{4}$ polymorphic variants. These findings suggest that the gene polymorphisms were not involved in any risk factor for pulmonary TB in the Colombian population [26]. The same result was obtained by Xue et al. [27], who discovered that these polymorphisms were rare in the Southeastern Chinese population and not linked to susceptibility to TB. Newport et al. [28] also have studied that, but result was that no association between $\mathrm{TLR}_{4}$ Asp299Gly and TB was observed.

The result of our study showed that it was negative. The reasons behind this result are first the size of the sample which was not enough. The second one is the geographic regions and genetic factors, because we were focused on the people of Northeast China in our work just only.

The purpose of this study is to determine why patients with T2DM easily develop pulmonary TB. Thus, we did not detect $\mathrm{TLR}_{4}$ gene polymorphisms in healthy cases and we did not compare changes in $\mathrm{TLR}_{4}$ gene polymorphisms among healthy cases, patients with T2DM, and patients with T2DMTB. Changes in $\mathrm{TLR}_{4}$ gene polymorphisms may have already occurred in most patients with T2DM. In this case, a false negative result may appear if a comparison was carried out between T2DM patients and patients suffering from T2DMTB only. Such a phenomenon would also confirm some reports that T2DM is characterized by chronic inflammation.

Some studies have recently mentioned that the risk genotypes of rs1927914 are significantly linked with diabetic foot ulcers [29]; the research team of Singh [30] also found that the combined genotype risks of TLR 4 SNPs rs10759931 
TABLE 3: Distributions of SNP genotypes and Hardy-Weinberg equilibrium.

\begin{tabular}{|c|c|c|c|c|c|}
\hline & \multirow{2}{*}{$\begin{array}{c}\text { T2DMTB } \\
\text { No. }(\%)\end{array}$} & \multirow{2}{*}{$\begin{array}{l}\text { T2DM } \\
\text { No. }(\%)\end{array}$} & \multirow{2}{*}{$p$ value } & \multicolumn{2}{|c|}{ Hardy-Weinberg } \\
\hline & & & & $x^{2}$ & $p$ value \\
\hline \multicolumn{6}{|c|}{ rs7873784 } \\
\hline GG & $243(86.17)$ & $236(83.69)$ & \multirow{3}{*}{0.19} & \multirow{3}{*}{0.56} & \multirow{3}{*}{0.46} \\
\hline GC & $35(12.41)$ & 45 (15.96) & & & \\
\hline $\mathrm{CC}$ & $4(1.42)$ & $1(0.35)$ & & & \\
\hline \multicolumn{6}{|c|}{ rs11536889 } \\
\hline GG & $176(61.97)$ & $181(64.41)$ & \multirow{3}{*}{0.83} & \multirow{3}{*}{0.81} & \multirow{3}{*}{0.37} \\
\hline GC & $93(32.75)$ & $86(30.61)$ & & & \\
\hline CC & $15(5.28)$ & $14(4.98)$ & & & \\
\hline \multicolumn{6}{|c|}{ rs1927914 } \\
\hline $\mathrm{TT}$ & $90(31.91)$ & $102(36.17)$ & \multirow{3}{*}{0.50} & \multirow{3}{*}{0.53} & \multirow{3}{*}{0.47} \\
\hline $\mathrm{CT}$ & $145(51.42)$ & $140(49.65)$ & & & \\
\hline $\mathrm{CC}$ & $47(16.67)$ & $40(14.18)$ & & & \\
\hline \multicolumn{6}{|c|}{ rs1927911 } \\
\hline $\mathrm{TT}$ & $97(34.28)$ & $96(34.16)$ & \multirow{3}{*}{0.48} & \multirow{3}{*}{2.92} & \multirow{3}{*}{0.09} \\
\hline $\mathrm{CT}$ & $139(49.12)$ & $148(52.67)$ & & & \\
\hline CC & $47(16.61)$ & $37(13.17)$ & & & \\
\hline \multicolumn{6}{|c|}{ rs1927907 } \\
\hline GG & $145(51.24)$ & $147(52.31)$ & \multirow{3}{*}{0.96} & \multirow{3}{*}{2.12} & \multirow{3}{*}{0.15} \\
\hline $\mathrm{AG}$ & $123(43.46)$ & $119(42.35)$ & & & \\
\hline AA & $15(5.30)$ & $15(5.34)$ & & & \\
\hline \multicolumn{6}{|c|}{ rs11536879 } \\
\hline $\mathrm{AA}$ & $230(82.44)$ & $215(77.62)$ & \multirow{3}{*}{0.20} & \multirow{3}{*}{1.04} & \multirow{3}{*}{0.31} \\
\hline $\mathrm{AG}$ & $41(14.70)$ & $56(20.22)$ & & & \\
\hline GG & $8(2.87)$ & $6(2.17)$ & & & \\
\hline
\end{tabular}

TABLE 4: Distributions of allelic genes of SNPs between patients with T2DMTB and patients with T2DM.

\begin{tabular}{|c|c|c|c|c|c|c|}
\hline \multirow{2}{*}{ SNP } & \multirow{2}{*}{ Allelic genes } & \multicolumn{2}{|c|}{ T2DMTB } & \multicolumn{2}{|c|}{$\mathrm{T} 2 \mathrm{DM}$} & \multirow{2}{*}{$p$ value } \\
\hline & & No. & $\%$ & No. & $\%$ & \\
\hline \multirow{2}{*}{ rs7873784 } & G allele & 521 & 92.36 & 517 & 91.67 & \multirow{2}{*}{0.74} \\
\hline & C allele & 43 & 7.64 & 47 & 8.33 & \\
\hline \multirow{2}{*}{ rs11536889 } & G allele & 445 & 78.35 & 448 & 79.72 & \multirow{2}{*}{0.61} \\
\hline & C allele & 123 & 21.65 & 114 & 20.28 & \\
\hline \multirow{2}{*}{ rs1927914 } & T allele & 325 & 57.62 & 344 & 60.99 & \multirow{2}{*}{0.43} \\
\hline & $\mathrm{C}$ allele & 229 & 42.38 & 220 & 39.01 & \\
\hline \multirow{2}{*}{ rs1927911 } & $\mathrm{T}$ allele & 333 & 58.83 & 340 & 60.50 & \multirow{2}{*}{0.59} \\
\hline & $\mathrm{C}$ allele & 233 & 41.17 & 222 & 39.50 & \\
\hline \multirow{2}{*}{ rs1927907 } & G allele & 413 & 72.97 & 413 & 73.49 & \multirow{2}{*}{0.89} \\
\hline & A allele & 153 & 27.03 & 149 & 26.51 & \\
\hline \multirow{2}{*}{ rs11536879 } & A allele & 501 & 89.78 & 486 & 87.73 & \multirow{2}{*}{0.30} \\
\hline & G allele & 57 & 10.22 & 68 & 12.27 & \\
\hline
\end{tabular}

(odds ratio [OR] 1.50, $p=0.05)$ and rs1927914 (OR 1.48, $p=$ $0.05)$ were significantly linked to retinopathy in T2DM. These works support the idea that T2DM is a chronic inflammatory disease. It is possible that T2DM patients already had TLR gene polymorphism. Therefore, we considered these points as the third reason.
Two groups of patients were included in our study. For each group, we concerned about the changing of $\mathrm{TLR}_{4}$ gene polymorphism and no changing of $\mathrm{TLR}_{4}$ levels in the blood. The reason of that was hidden behind the changing in the $\mathrm{TLR}_{4}$ gene, because serum $\mathrm{TLR}_{4}$ is a sensitivity index but not a specific index. Chronic inflammation could directly lead to 
TABLE 5: Associations between the SNPs of $\mathrm{TLR}_{4}$ and DMTB risk.

\begin{tabular}{|c|c|c|c|c|}
\hline Genotype & Crude OR (95\% CI) & $p$ value & Adjusted OR $(95 \% \mathrm{CI})^{*}$ & $p$ value \\
\hline \multicolumn{5}{|l|}{ rs7873784 } \\
\hline GG & 1.00 & & 1.00 & \\
\hline GC & $0.76(0.47-1.22)$ & 0.25 & $0.69(0.42-1.14)$ & 0.15 \\
\hline $\mathrm{CC}$ & $3.89(0.43-35.01)$ & 0.23 & $3.16(0.33-30.74)$ & 0.32 \\
\hline $\mathrm{CC} /(\mathrm{GG}+\mathrm{GC})$ & $4.04(0.45-36.41)$ & 0.21 & $3.34(0.34-32.38)$ & 0.30 \\
\hline$(\mathrm{GC}+\mathrm{CC}) / \mathrm{GG}$ & $0.82(0.52-1.31)$ & 0.41 & $0.75(0.46-1.22)$ & 0.25 \\
\hline \multicolumn{5}{|l|}{ rs11536889 } \\
\hline GG & 1.00 & & 1.00 & \\
\hline GC & $1.12(0.78-1.60)$ & 0.54 & $1.04(0.71-1.51)$ & 0.85 \\
\hline $\mathrm{CC}$ & $1.11(0.52-2.36)$ & 0.79 & $1.08(0.49-2.39)$ & 0.85 \\
\hline $\mathrm{CC} /(\mathrm{GG}+\mathrm{GC})$ & $1.07(0.51-2.26)$ & 0.86 & $1.07(0.49-2.34)$ & 0.87 \\
\hline$(\mathrm{GC}+\mathrm{CC}) / \mathrm{GG}$ & $1.12(0.79-1.57)$ & 0.53 & $1.04(0.73-1.49)$ & 0.82 \\
\hline \multicolumn{5}{|l|}{ rs1927914 } \\
\hline TT & 1.00 & & 1.00 & \\
\hline $\mathrm{CT}$ & $1.17(0.81-1.69)$ & 0.39 & $1.25(0.85-1.84)$ & 0.25 \\
\hline $\mathrm{CC}$ & $1.33(0.80-2.21)$ & 0.27 & $1.35(0.80-2.29)$ & 0.27 \\
\hline $\mathrm{CC} /(\mathrm{TT}+\mathrm{CT})$ & $1.21(0.77-1.91)$ & 0.42 & $1.18(0.73-1.91)$ & 0.49 \\
\hline$(\mathrm{CT}+\mathrm{CC}) / \mathrm{TT}$ & $1.21(0.85-1.71)$ & 0.29 & $1.28(0.89-1.84)$ & 0.19 \\
\hline \multicolumn{5}{|l|}{ rs1927911 } \\
\hline $\mathrm{TT}$ & 1.00 & & 1.00 & \\
\hline $\mathrm{CT}$ & $0.93(0.65-1.34)$ & 0.70 & $0.93(0.63-1.36)$ & 0.71 \\
\hline $\mathrm{CC}$ & $1.26(0.75-2.10)$ & 0.38 & $1.22(0.72-2.09)$ & 0.46 \\
\hline $\mathrm{CC} /(\mathrm{TT}+\mathrm{CT})$ & $1.31(0.82-2.09)$ & 0.25 & $1.28(0.79-2.08)$ & 0.36 \\
\hline$(\mathrm{CT}+\mathrm{CC}) / \mathrm{TT}$ & $1.00(0.70-1.41)$ & 0.98 & $0.99(0.69-1.43)$ & 0.96 \\
\hline \multicolumn{5}{|l|}{ rs1927907 } \\
\hline GG & 1.00 & & 1.00 & \\
\hline AG & $1.05(0.75-1.47)$ & 0.79 & $1.03(0.72-1.48)$ & 0.86 \\
\hline AA & $1.01(0.48-2.15)$ & 0.97 & $0.95(0.44-2.05)$ & 0.89 \\
\hline $\mathrm{AA} /(\mathrm{GG}+\mathrm{AG})$ & $0.99(0.48-2.07)$ & 0.98 & $0.93(0.44-1.99)$ & 0.85 \\
\hline$(\mathrm{AG}+\mathrm{AA}) / \mathrm{GG}$ & $1.04(0.75-1.45)$ & 0.80 & $1.02(0.72-1.44)$ & 0.90 \\
\hline \multicolumn{5}{|l|}{ rs11536879 } \\
\hline AA & 1.00 & & 1.00 & \\
\hline AG & $0.68(0.44-1.07)$ & 0.09 & $0.68(0.43-1.08)$ & 0.10 \\
\hline GG & $1.25(0.43-3.65)$ & 0.69 & $1.35(0.45-4.04)$ & 0.59 \\
\hline GG/(AA + AG) & $1.33(0.46-3.89)$ & 0.60 & $1.44(0.48-4.31)$ & 0.51 \\
\hline$(\mathrm{AG}+\mathrm{GG}) / \mathrm{AA}$ & $0.74(0.49-1.12)$ & 0.16 & $0.75(0.48-1.15)$ & 0.19 \\
\hline
\end{tabular}

Note. ${ }^{*}$ Age, gender, BMI, smoking, drinking, insulin use, and hypoglycemic drug use were adjusted.

changes in $\mathrm{TLR}_{4}$ in the blood or other gene polymorphisms that could lead to $\mathrm{TLR}_{4}$ changes in the blood. Our study was limited by considering just $\mathrm{TLR}_{4}$ gene polymorphisms. Other inflammatory gene polymorphisms that promote development of T2DMTB may exist.

The results of this study reveal that $\mathrm{TLR}_{4}$ changes at the molecular level are insignificant because the changes at the gene level may be not significant. Our results also demonstrated no significant link between the six SNPs of $\mathrm{TLR}_{4}$ studied in this work and the susceptibility of patients with T2DMTB in Northeast China. Future studies may be performed to determine the causes of T2DMTB from the perspective of genetics. We aim to determine the marker gene polymorphism in T2DM and show how it can be complicated by TB.

\section{Competing Interests}

The authors declare that there are no competing interests regarding the publication of this paper.

\section{References}

[1] M. Crook, "Type 2 diabetes mellitus: a disease of the innate immune system? An update," Diabetic Medicine, vol. 21, no. 3, pp. 203-207, 2004. 
[2] H. Kolb and T. Mandrup-Poulsen, "An immune origin of type 2 diabetes?" Diabetologia, vol. 48, no. 6, pp. 1038-1050, 2005.

[3] G. G. L. Biondi-Zoccai, A. Abbate, G. Liuzzo, and L. M. Biasucci, "Atherothrombosis, inflammation, and diabetes," Journal of the American College of Cardiology, vol. 41, no. 7, pp. 1071-1077, 2003.

[4] G. García-Elorriaga, L. Vera-Ramírez, G. del Rey-Pineda, and C. González-Bonilla, “-592 and -1082 interleukin-10 polymorphisms in pulmonary tuberculosis with type 2 diabetes," Asian Pacific Journal of Tropical Medicine, vol. 6, no. 7, pp. 505-509, 2013.

[5] C. A. Janeway Jr. and R. Medzhitov, "Innate immune recognition," Annual Review of Immunology, vol. 20, pp. 197-216, 2002.

[6] R. Medzhitov and C. Janeway Jr., "Innate immunity," The New England Journal of Medicine, vol. 343, no. 5, pp. 338-344, 2000.

[7] S. T. Qureshi, L. Larivière, G. Leveque et al., "Endotoxintolerant mice have mutations in toll-like receptor 4 (Tlr4)," Journal of Experimental Medicine, vol. 189, no. 4, pp. 615-625, 1999.

[8] L. A. J. O’Neill, K. A. Fitzgerald, and A. G. Bowie, “The TollIL-1 receptor adaptor family grows to five members," Trends in Immunology, vol. 24, no. 6, pp. 286-289, 2003.

[9] D. Ning and Y. Yongming, "Toll-like receptors immunology research progress," Infection, Immunity \& Repair, vol. 9, no. 3, pp. 177-180, 2008.

[10] A. Aderem and R. J. Ulevitch, "Toll-like receptors in the induction of the innate immune response," Nature, vol. 406, no. 6797, pp. 782-787, 2000.

[11] Y.-C. Lu, W.-C. Yeh, and P. S. Ohashi, "LPS/TLR4 signal transduction pathway," Cytokine, vol. 42, no. 2, pp. 145-151, 2008.

[12] M. Buraczynska, I. Baranowicz-Gaszczyk, J. Tarach, and A. Ksiazek, "Toll-like receptor 4 gene polymorphism and early onset of diabetic retinopathy in patients with type 2 diabetes," Human Immunology, vol. 70, no. 2, pp. 121-124, 2009.

[13] Z.-S. Jiang, S.-X. Wang, H.-X. Jia, J. Wang, and Y.-T. Liu, "Association of toll-like receptor 4 polymorphisms with type 2 diabetes mellitus," Inflammation, vol. 36, no. 1, pp. 251-257, 2013.

[14] C. Maldonado-Bernal, O. A. Trejo-de la, M. E. SánchezContreras, N. Wacher-Rodarte, J. Torres, and M. Cruz, "Low frequency of Toll-like receptors 2 and 4 gene polymorphisms in Mexican patients and their association with type 2 diabetes," International Journal of Immunogenetics, vol. 38, no. 6, pp. 519523, 2011.

[15] F. F. Yuan, K. Marks, M. Wong et al., "Clinical relevance of TLR2, TLR4, CD14 and Fc $\gamma$ RIIA gene polymorphisms in Streptococcus pneumoniae infection," Immunology and Cell Biology, vol. 86, no. 3, pp. 268-270, 2008.

[16] C. Guarner-Argente, E. Sánchez, S. Vidal et al., “Toll-like receptor $4 \mathrm{D} 299 \mathrm{G}$ polymorphism and the incidence of infections in cirrhotic patients," Alimentary Pharmacology and Therapeutics, vol. 31, no. 11, pp. 1192-1199, 2010.

[17] M. Surbatovic, K. Grujic, B. Cikota et al., "Polymorphisms of genes encoding tumor necrosis factor-alpha, interleukin-10, cluster of differentiation-14 and interleukin-1ra in critically ill patients," Journal of Critical Care, vol. 25, no. 3, pp. 542.e1542.e8, 2010.

[18] A. Q. Zhang, C. L. Yue, W. Gu et al., "Association between CD14 promoter $-159 \mathrm{C} / \mathrm{T}$ polymorphism and the risk of sepsis and mortality: a systematic review and meta-analysis," PLoS ONE, vol. 8, no. 8, Article ID e71237, 2013.
[19] E. Lorenz, M. Jones, C. Wohlford-Lenane et al., "Genes other than TLR4 are involved in there sponse to inhaled LPS," American Journal of Physiology-Lung Cellular and Molecular Physiology, vol. 281, no. 5, pp. 1106-1114, 2001.

[20] N. C. Arbour, E. Lornz, B. C. Schutte et al., "TLR4 mutations are associated with endotoxin hyporesponsiveness in humans," Nature Genetics, vol. 25, no. 2, pp. 187-191, 2000.

[21] T. E. West, W. Chierakul, N. Chantratita et al., “Toll-like receptor 4 region genetic variants are associated with susceptibility to melioidosis," Genes and Immunity, vol. 13, no. 1, pp. 38-46, 2012.

[22] Y. F. Qing, J. G. Zhou, Q. B. Zhang et al., "Association of TLR4 Gene rs2149356 polymorphism with primary gouty arthritis in a case-control study," PLoS ONE, vol. 8, no. 5, Article ID e64845, 2013.

[23] L. Wu, Y. Hu, D. Li, W. Jiang, and B. Xu, "Screening toll-like receptor markers to predict latent tuberculosis infection and subsequent tuberculosis disease in a Chinese population," $B M C$ Medical Genetics, vol. 16, no. 1, article 19, 2015.

[24] N. Arji, M. Busson, G. Iraqi et al., "Genetic diversity of TLR2, TLR4, and VDR loci and pulmonary tuberculosis in moroccan patients," Journal of Infection in Developing Countries, vol. 8, no. 4, pp. 430-440, 2014.

[25] D. Jahantigh, S. Salimi, R. Alavi-Naini, A. Emamdadi, H. Owaysee Osquee, and F. Farajian Mashhadi, "Association between TLR4 and TLR9 gene polymorphisms with development of pulmonary tuberculosis in Zahedan, Southeastern Iran," The Scientific World Journal, vol. 2013, Article ID 534053, 7 pages, 2013.

[26] D. Sánchez, C. Lefebvre, J. Rioux, L. F. García, and L. F. Barrera, "Evaluation of Toll-like receptor and adaptor molecule polymorphisms for susceptibility to tuberculosis in a Colombian population," International Journal of Immunogenetics, vol. 39, no. 3, pp. 216-223, 2012.

[27] Y. Xue, Z. Q. Zhao, H. J. Wang et al., “Toll-like receptors 2 and 4 gene polymorphisms in a southeastern Chinese population with tuberculosis," International Journal of Immunogenetics, vol. 37, no. 2, pp. 135-138, 2010.

[28] M. J. Newport, A. Allen, A. A. Awomoyi et al., "The toll-like receptor 4 Asp299Gly variant: no influence on LPS responsiveness or susceptibility to pulmonary tuberculosis in The Gambia," Tuberculosis, vol. 84, no. 6, pp. 347-352, 2004.

[29] S. Singh, V. K. Singh, N. K. Agrawal, S. K. Gupta, and K. Singh, "Association of toll-like receptor 4 polymorphisms with diabetic foot ulcers and application of artificial neural network in DFU risk assessment in type 2 diabetes patients," BioMed Research International, vol. 2013, Article ID 318686, 9 pages, 2013.

[30] K. Singh, S. Kant, V. K. Singh, N. K. Agrawal, and S. K. Gupta, "Toll-like receptor 4 polymorphisms and their haplotypes modulate the risk of developing diabetic retinopathy in type 2 diabetes patients," Molecular Vision, vol. 20, pp. 704-713, 2014. 

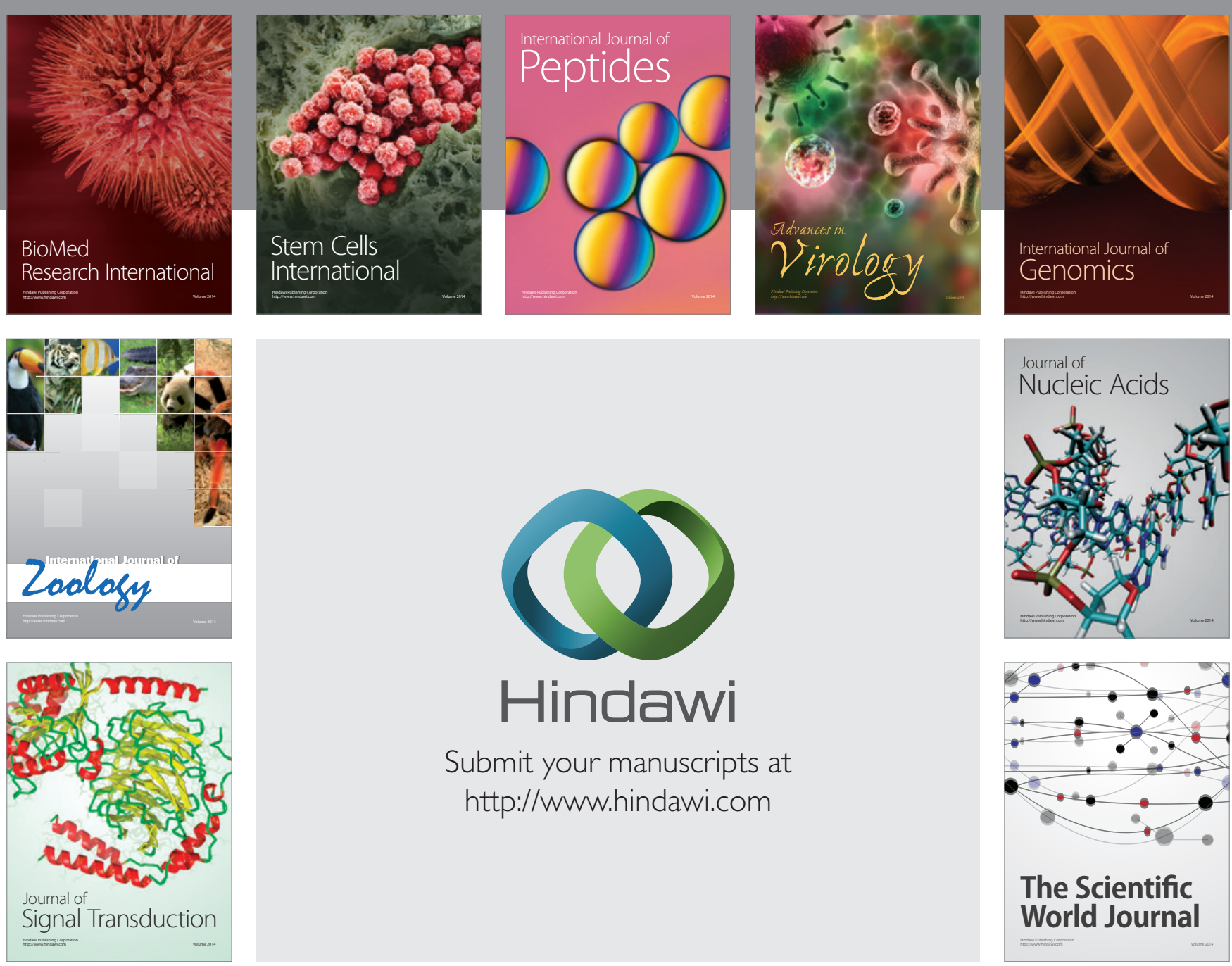

Submit your manuscripts at

http://www.hindawi.com
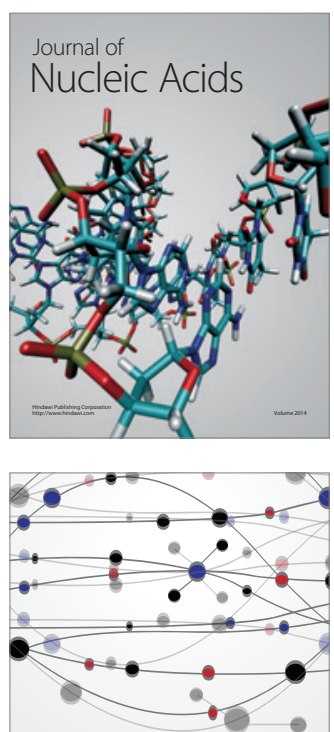

The Scientific World Journal
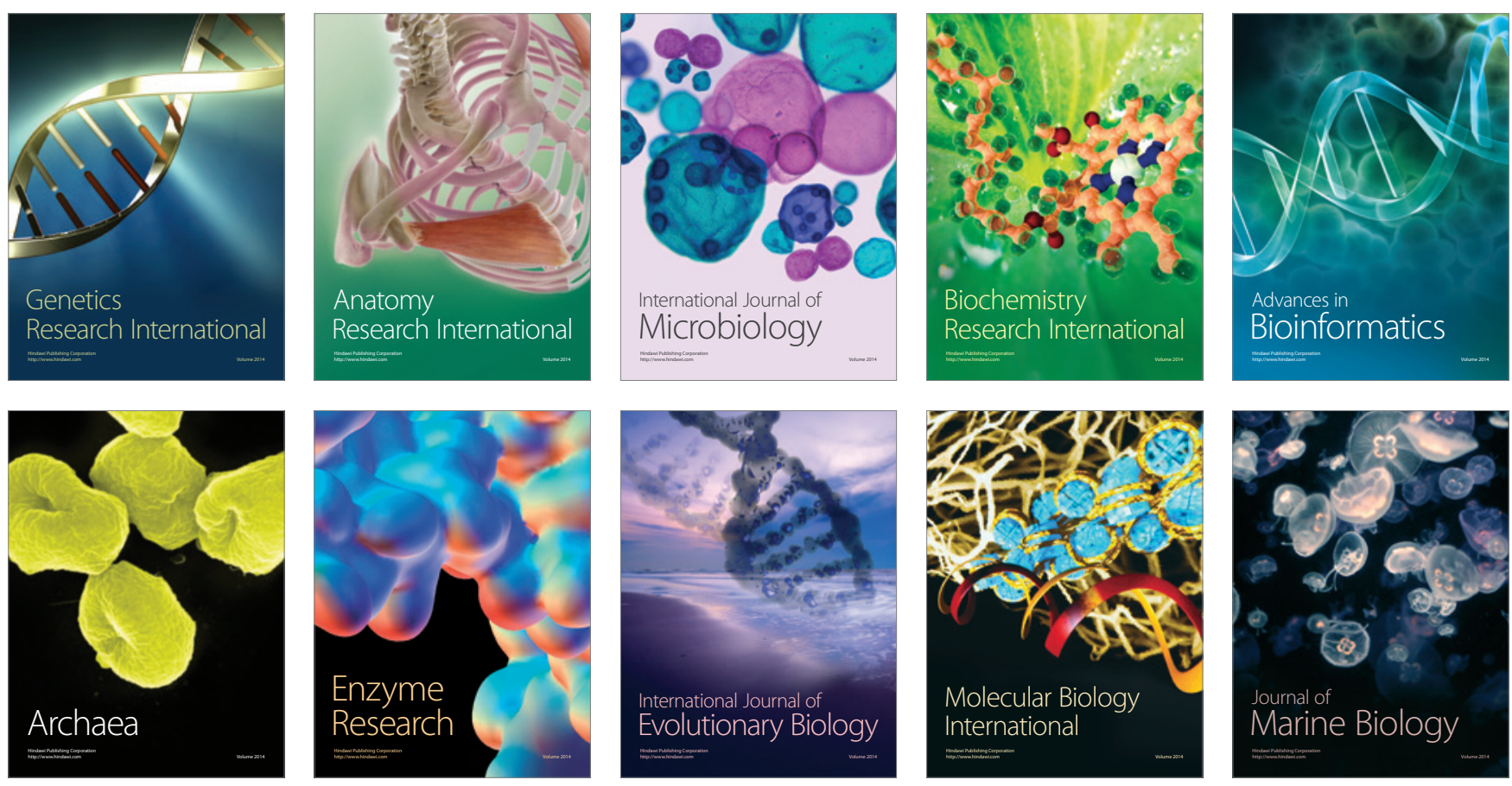